\title{
High self-assessment of disability and the surgeon's recommendation against surgical intervention may negatively impact satisfaction scores in patients with spinal disorders
}

\author{
Marcus D. Mazur, MD, Sara McEvoy, PA, Meic H. Schmidt, MD, MBA, \\ and Erica F. Bisson, MD, MPH \\ Department of Neurosurgery, Clinical Neurosciences Center, University of Utah, Salt Lake City, Utah
}

OBJECT Patient satisfaction scores have become a common metric for health care quality. Because satisfaction scores are right-skewed, even small differences in mean scores can have a large impact. Little information, however, is available on the specific factors that play a role in satisfaction in patients with spinal disorders. The authors investigated whether disability severity and the surgeon's recommendation for or against surgical intervention were associated with patient satisfaction scores.

METHODS The authors conducted a retrospective cohort study involving adult patients who were referred to a spine surgeon for an outpatient evaluation of back pain. Patients completed the Oswestry Disability Index (ODI) before their clinic appointment and a Press Ganey patient satisfaction survey after their visit. Patients were grouped by self-assessed disability severity: mild to moderate $(\mathrm{ODI}<40 \%)$ and severe $(\geq 40 \%)$. Satisfaction scores were graded from 0 (very poor) to 100 (very good). Nonparametric tests were used to evaluate the association between patient satisfaction and current disability self-assessment. The authors also investigated whether the surgeon's recommendation against surgery negatively affected patient satisfaction.

RESULTS One hundred thirty patients completed the ODI questionnaire before and satisfaction surveys after seeing a spine surgeon for a new outpatient back pain consultation. Of these, 68 patients had severe disability, 62 had mild to moderate disability, 67 received a recommendation for surgery, and 63 received a recommendation against surgery. Composite satisfaction scores were lower among patients who had severe disability than among those with mild to moderate disability (median [interquartile range]: 91.7 [83.7-96.4] vs 95.8 [91.0-99.3], respectively; $p=0.0040$ ). Patients who received a recommendation against surgery reported lower satisfaction scores than those who received a recommendation for surgery (91.7 [83.5-95.8] vs 95.8 [88.5-99.8]; $p=0.0059)$.

CONCLUSIONS High self-assessment of disability and a surgeon's recommendation against surgical intervention are associated with lower satisfaction scores in patients with spinal disorders.

http://thejns.org/doi/abs/10.3171/2014.10.SPINE14264

KEY WORDS patient satisfaction; Oswestry Disability Index; back pain; health services research; surgeon recommendation

$\mathrm{T}$ HE Patient Protection and Affordable Care Act has identified experience of care as a priority. Surveys of patients' satisfaction regarding their health care experience are being used for staff performance evaluation, goal setting, and even reimbursement for surgical care. ${ }^{4}$ With implementation of the Affordable Care Act in 2014, the use of patient satisfaction metrics is likely to increase. These policies reflect the perception that patient satisfaction is a comprehensive indicator of health care quality. ${ }^{5,29,35,40}$ Recent research, however, demonstrates that patient satisfaction surveys do not necessarily reflect technical quality, such as compliance with evidencebased guidelines of surgical care. ${ }^{27}$ Paradoxically, patient satisfaction may actually correlate with poorer health outcomes, because of increased or, in some cases, excessive utilization of the health care system. ${ }^{8}$ A wide variety

ABBREVIATIONS IOM = Institute of Medicine; IQR = interquartile range; ODI = Oswestry Disability Index; OR = odds ratio. SUBMITTED May 19, 2014. ACCEPTED October 23, 2014. 
of factors influence satisfaction, many of which may be unique to the individual or preexisting. Patients with poor physical health tend to be less satisfied with their medical care..$^{13,15,26}$ Furthermore, this relationship appears to be unidirectional, as health status predicts satisfaction rather than vice versa. ${ }^{14}$ We designed a study to explore the relationship between disability and satisfaction in patients with spinal disorders. Because patients are frequently referred to a spine surgeon specifically for a surgical opinion, we also investigated whether the surgeon's recommendation for or against surgical intervention affected satisfaction scores. We hypothesized that satisfaction would be influenced by these factors that do not reflect either the appropriateness or the quality of care provided.

\section{Methods \\ Data Collection}

We conducted a retrospective cohort study of adult patients who were seen for initial consultations for back pain in our spine clinic between 2011 and 2013. Patients who had not been seen previously in the spine clinic and those who were not seen by a spine surgeon at the University of Utah in the previous 3 years were included if they received a recommendation for or against surgical intervention. Each patient was evaluated by one of 5 neurosurgeons. Of these patients, we included in our analysis all patients who completed an Oswestry Disability Index (ODI) questionnaire before their consultation and a patient satisfaction survey after their clinic appointment. Patients were mailed the ODI questionnaire 1 week prior to their clinic appointment and were asked to bring the completed questionnaire to their appointment. Patients who forgot their ODI questionnaires were asked to complete one when they checked in on the day of their clinic appointment. Satisfaction surveys were sent by mail approximately 1 week after the clinic appointment, and these were returned via postagepaid envelopes. This is the standard method of survey administration used at our institution for assessment of patient satisfaction. No additional reminders or incentives were used to encourage survey participation.

A Press Ganey medical practice survey (Press Ganey Associates, Inc.) was used as the instrument to measure outpatient patient satisfaction. This survey is divided into 6 sections, each comprising 2-10 items: access, moving through your visit, nurse/assistant, care provider, personal issues, and overall assessment. Each item corresponds to one of several components of an outpatient health care encounter such as ease of scheduling appointments and courtesy of clerical staff (access), wait times and delays (moving through your visit), interactions with the nurse or medical assistant, the patient-provider encounter, staff attentiveness to privacy and patient safety (personal issues), the ability of the staff to work together, and the likelihood of recommending the practice to others (overall assessment). Scores were transformed from the 5-point Likert scale used in the medical practice survey to a 100 -point satisfaction scale graded from 0 (very poor) to 100 (very good). The mean score of each section was used in the data analysis. A composite average of each section score was also calculated. Sections with incomplete responses were excluded from analysis.
Disability was self-assessed using the Oswestry Disability Index (ODI), a 10-question, low back-specific instrument used to measure self-rated pain and disability? Scores are based on patient responses to 10 sections designed to assess pain, function, and limitations of various activities of daily living. The ODI is deliberately focused on physical activities and not the psychological consequences of acute or chronic pain.? We used the ODI version 2.0 with some minor modifications for brevity.

\section{Analysis}

Our first objective was to determine whether high selfassessment of disability, as measured by the ODI, was associated with lower satisfaction scores in patients referred to a spine surgeon for back pain. The ODI scoring results were transformed to percentage scores to account for questions that were unanswered. Patients were grouped by severity of disability according to the ODI percentage score, in a method used by others: ${ }^{7,36}$ mild to moderate disability (ODI score $<40 \%$ ) and severe disability $(\geq 40 \%)$. Satisfaction scores were compared between groups. Our second objective was to determine whether the neurosurgeon's recommendation for or against surgical intervention affected satisfaction scores. Patients were then stratified according to the surgeon's treatment recommendation, and satisfaction scores were compared. Nonparametric tests were used for statistical analysis because satisfaction scores had a skewed distribution. The Mann-WhitneyWilcoxon test was used to determine whether disability severity (mild to moderate vs severe) or the surgeon's recommendation for or against surgery were associated with satisfaction scores. Multivariate linear regression analysis was performed to identify potential confounders, such as age, sex, surgeon, and previous spine surgery. A p value < 0.05 was considered statistically significant. Calculations were performed with R software (version 3.0.2, R Foundation for Statistical Computing, http://www.R-project.org).

This study was conducted in accordance with the policies of the institutional review board at our institution.

\section{Results}

During the study period, 577 patients were mailed patient satisfaction surveys after an outpatient spine clinic visit. Of these, 297 patients were referred to a spine surgeon for a consultation to determine whether a surgical intervention was recommended for management of the patient's condition. Of these, 219 patients were seen for back pain, and 130 of these 219 patients had completed an ODI questionnaire prior to their consultation in addition to the post-visit satisfaction survey. These patients comprised our study cohort.

Among the 130 patients, mean age was 61.7 years, and 70 patients $(54 \%)$ were male. Forty-six patients $(35 \%)$ had undergone prior spine surgery. Symptom duration was 1 year or greater in $68 \%$. The mean $( \pm \mathrm{SD})$ ODI percentage score was $37.8 \% \pm 17.7 \%$. The median composite satisfaction score was 94.0 (interquartile range [IQR] 86.5-98.4).

The characteristics of the study groups are described in Table 1. Sixty-seven patients received a recommendation for surgery and 63 received a recommendation against 
TABLE 1. Characteristics of 130 patients who completed the ODI evaluation and satisfaction survey*

\begin{tabular}{|c|c|c|c|c|}
\hline Variable & $\begin{array}{l}\text { Recommendation } \\
\text { for Surgery }\end{array}$ & $\begin{array}{l}\text { Recommendation } \\
\text { Against Surgery }\end{array}$ & $\mathrm{ODI}<40 \%$ & $\mathrm{ODI} \geq 40 \%$ \\
\hline No. of patients & 67 & 63 & 68 & 62 \\
\hline No. of males (\%) & $36(54)$ & $34(54)$ & $37(54)$ & $33(62)$ \\
\hline Mean age (yrs) & $60.6 \pm 11.7$ & $62.9 \pm 12.6$ & $62.1 \pm 11.1$ & $61.3 \pm 13.2$ \\
\hline Prior spine surgery (\%) & $25(37)$ & $21(33)$ & $18(26)$ & $28(41)$ \\
\hline \multicolumn{5}{|l|}{ ODI (\%) } \\
\hline Mean & $37.6 \pm 17.6$ & $38.0 \pm 17.9$ & $23.9 \pm 9.6$ & $53.1 \pm 10.3$ \\
\hline Range & $2-78$ & $6-84$ & 2-38 & $40-84$ \\
\hline Surgery recommendation (\%) & $67(100)$ & $0(0)$ & $35(51)$ & $32(52)$ \\
\hline Median composite satisfaction score (IQR) & $95.8(88.5-99.8)$ & $91.7(83.5-95.8)$ & $95.8(91.0-99.3)$ & $91.5(83.7-96.4)$ \\
\hline
\end{tabular}

surgery. The mean ODI percentage scores were similar in these 2 groups $(37.6 \% \pm 17.6 \%$ vs $38.0 \% \pm 17.9 \%$, respectively; $p=0.92$ ). Lower satisfaction scores were observed in patients who received a recommendation against surgery than in those who received a recommendation for surgery (Table 2). This trend was seen for the following satisfaction survey items: access (median [IQR] 81.3 [75.0-100] vs 93.8 [81.3-100], $\mathrm{p}=0.0046$ ), moving through your visit (75.0 [75.0-100] vs 87.5 [75.0-100], $p=0.017)$, nurse/assistant (100 [87.5-100] vs 100 [100-100], $\mathrm{p}=0.038)$, personal issues $(100$ [81.3-100] vs 100 [92.8-100], $\mathrm{p}=0.024)$, and the composite average (91.7 [83.5-95.8] vs 95.8 [88.599.8], $\mathrm{p}=0.0059$ ).

Sixty-eight patients had mild to moderate disability (ODI $<40 \%$ ) and 62 had severe disability (ODI $\geq 40 \%$ ). The mean ODI percentage score was $23.9 \% \pm 9.6 \%$ in the mild to moderate group and $53.1 \% \pm 10.3 \%$ in the severe group. Thirty-five patients (51\%) in the mild to moderate disability group received a recommendation for surgery versus 32 patients $(52 \%)$ in the severe disability group. Lower satisfaction scores were observed in patients with severe disability compared with those with mild to moderate disability (Table 3). This trend was observed for the following satisfaction survey items: moving through your visit (median [IQR] 75.0 [62.5-87.5] vs 87.5 [75.0$100], \mathrm{p}=0.0017)$, care provider $(100$ [94.6-100] vs 100 [97.5-100], $\mathrm{p}=0.011)$, personal issues (93.8 [81.3-100] vs 100 [93.8-100], $\mathrm{p}=0.0011)$, overall assessment $(100$
[87.5-100] vs 100 [100-100], $\mathrm{p}=0.034$, and the composite average (91.5 [83.7-96.4] vs 95.8 [91.0-99.2], $\mathrm{p}=0.0040$ ).

Multivariate linear regression analysis was performed to identify potential confounders, including age, sex, surgeon, and previous spine surgery. Age, sex, surgeon, and previous spine surgery were not associated with satisfaction scores. ODI severity and the surgeon's recommendation retained significance as factors that predicted satisfaction scores: odds ratio (OR) $1.06,95 \%$ CI 1.02-1.10, $\mathrm{p}=0.0029$ and OR 1.06, 95\% CI 1.02-1.10, $\mathrm{p}=0.0026$, respectively. Furthermore, ODI severity and the surgeon's recommendation did not demonstrate interdependence with Fisher's exact test $(p=1.00)$.

\section{Discussion}

\section{Self-Assessed Disability and Satisfaction}

We found that among patients presenting for spine consultations, high self-assessment of disability was associated with lower patient satisfaction. Patients with severe disability (ODI $\geq 40 \%$ ) reported lower satisfaction scores than those with mild to moderate disability (ODI $<40 \%$ ). These findings are supported by multiple studies identifying that patients who have worse physical health are less satisfied with their medical care than patients in better health. ${ }^{13,17,20,26,32}$ Sicker patients may develop a negative affect that becomes attached to the care provider and to their encounters with the health care system, which may

TABLE 2. Satisfaction scores for patients who received a recommendation for or against surgery

\begin{tabular}{|c|c|c|c|c|c|}
\hline \multirow[b]{2}{*}{ Section } & \multicolumn{2}{|c|}{ Recommendation for Surgery } & \multicolumn{2}{|c|}{ Recommendation Against Surgery } & \multirow[b]{2}{*}{ p Value* } \\
\hline & Mean \pm SD & Median (IQR) & Mean \pm SD & Median (IQR) & \\
\hline Access & $90.6 \pm 10.8$ & $93.8(81.3-100)$ & $84.1 \pm 14.2$ & $81.3(75.0-100)$ & 0.0046 \\
\hline Moving through your visit & $85.8 \pm 16.5$ & $87.5(75.0-100)$ & $76.2 \pm 23.6$ & $75.0(75.0-100)$ & 0.017 \\
\hline Nurse/assistant & $97.2 \pm 7.2$ & $100(100-100)$ & $92.1 \pm 16.5$ & $100(87.5-100)$ & 0.038 \\
\hline Care provider & $97.3 \pm 6.3$ & $100(97.1-100)$ & $93.2 \pm 15.9$ & $100(94.7-100)$ & 0.40 \\
\hline Personal issues & $95.0 \pm 8.5$ & $100(92.8-100)$ & $90.1 \pm 13.5$ & $100(81.3-100)$ & 0.024 \\
\hline Overall assessment & $95.6 \pm 11.7$ & $100(100-100)$ & $93.4 \pm 16.6$ & $100(100-100)$ & 0.32 \\
\hline Composite average & $93.6 \pm 6.9$ & $95.8(88.5-99.8)$ & $88.3 \pm 13.2$ & $91.7(83.5-95.8)$ & 0.0059 \\
\hline
\end{tabular}

* Mann-Whitney-Wilcoxon test. Bold type indicates statistical significance. 
TABLE 3. Patient satisfaction scores by ODI score

\begin{tabular}{|c|c|c|c|c|c|}
\hline \multirow[b]{2}{*}{ Section } & \multicolumn{2}{|c|}{$\mathrm{ODI}<40 \%$} & \multicolumn{2}{|c|}{$\mathrm{ODI}>40 \%$} & \multirow[b]{2}{*}{$p$ Value } \\
\hline & Mean & Median (IQR) & Mean & Median (IQR) & \\
\hline Access & $89.0 \pm 11.8$ & $93.8(81.3-100)$ & $85.8 \pm 13.9$ & $87.5(81.3-100)$ & 0.20 \\
\hline Moving through your visit & $87.1 \pm 15.6$ & $87.5(75.0-100)$ & $74.8 \pm 23.6$ & $75.0(62.5-87.5)$ & 0.0017 \\
\hline Nurse/assistant & $95.9 \pm 10.0$ & $100(100-100)$ & $93.5 \pm 15.2$ & $100(87.5-100)$ & 0.18 \\
\hline Care provider & $97.8 \pm 5.3$ & $100(97.5-100)$ & $92.5 \pm 16.2$ & $100(94.6-100)$ & 0.011 \\
\hline Personal issues & $95.8 \pm 7.9$ & $100(93.8-100)$ & $89.1 \pm 13.6$ & $93.8(81.3-100)$ & 0.0011 \\
\hline Overall assessment & $96.9 \pm 9.7$ & $100(100-100)$ & $91.8 \pm 17.8$ & $100(87.5-100)$ & 0.034 \\
\hline Composite average & $93.8 \pm 6.7$ & $95.8(91.0-99.2)$ & $88.0 \pm 13.3$ & $91.5(83.7-96.4)$ & 0.0040 \\
\hline
\end{tabular}

* Mann-Whitney-Wilcoxon test. Bold type indicates statistical significance.

translate to lower satisfaction scores. ${ }^{15,26}$ Dissatisfaction tends to persist in patients with poor health across a variety of health care environments. ${ }^{18}$ Consequently, investigators using satisfaction to evaluate the process, content, or structure of medical care should control for severity of disability, along with health status, age, sociodemographics, and other correlates of satisfaction to avoid incorrectly attributing problems to the health care system that may actually reside in the patient. ${ }^{5,6,11,17,18,26,37}$

Because surveys of patients are increasingly used to measure health care quality, verifying that patients' responses serve as a reliable indicator for quality is cru-

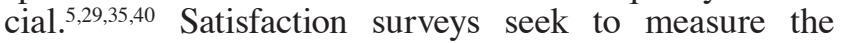
consumer experience as it relates to the administrative processes needed to deliver care; however, patients can describe high levels of satisfaction while also describing experiences that are suboptimal. ${ }^{22}$ The satisfaction survey we used in this study attempted to capture the experience both as a patient and as a consumer. The physician encounter encompasses only one of several components of the health care experience that the patient is asked to rate. Other survey items addressed ease of scheduling appointments and courtesy of clerical staff, wait times and delays, interactions with the nurse or medical assistant, attentiveness to privacy, needs, and patient safety, staff cohesiveness and ability to work together, and the likelihood of recommending the practice to others. Knowledge of how these surveys are conducted, the items measured in the surveys, and the factors associated with positive and negative scores are essential for physicians to compete more effectively as performance evaluations and reimbursements become linked to survey results. This policy can be expected to continue as studies report that satisfaction is highly correlated with willingness to recommend the physician or practice to others. ${ }^{22,34}$

In our study population, severity of disability was associated with lower patient satisfaction for the following sections: "Personal issues," "Moving through your visit," "Care provider," "Overall assessment," and for the composite average satisfaction score. Patients who received a recommendation against surgical intervention also had lower satisfaction scores for 4 of 6 survey items. Although the absolute value of the differences between groups may be small, in surveys of patient satisfaction even small differences can have a large impact. Assessments of satisfaction tend not to have normal distributions, and the results are often skewed., ${ }^{9,22}$ For example, because provider scores tend to be very positive, even slightly lower scores may translate to large differences in percentile ranking among peers. As health care systems move toward linking reimbursement with survey results, physicians should be aware of the factors that may negatively affect their scores.

\section{Timeliness}

The "Moving through your visit" section consists of 2 items that address wait time and delays. We found that patients with higher self-assessment of pain and disability reported lower scores for these survey items. There is a strong inverse relationship with wait times and patient satisfaction in physician offices. ${ }^{23,31}$ This relationship applies to the amount of time patients spend in both the waiting room and the examination room. ${ }^{23}$ In our study population, the negative impact of poor health status appears to magnify this relationship further. Patients who spend less time waiting are more likely to recommend the practice to others. ${ }^{33}$ The Institute of Medicine (IOM) identified timeliness as one of the 6 aims for improving the quality of health care. ${ }^{19}$ Practices that decrease wait times have seen improvements in the overall satisfaction of their patients, ${ }^{31}$ but despite its relevance to patient satisfaction, timeliness of care in the clinic setting is among the least studied IOM aims. ${ }^{23}$

A key component of the wait time issue is perception. Patients who have a scheduled appointment at a certain time may perceive wait times to be longer and become dissatisfied because of a perception that the provider is breaking a promise. Conversely, patients may tolerate waiting as long as the feel they get adequate time with their physician, ${ }^{1}$ although this will negatively affect how long other patients have to wait to see that physician. The literature on marketing suggests that the perception of waiting time can be altered. Some propose that changes that make the service environment more pleasing, such as music, lighting, temperature, color, and furnishings, may shorten the perceived wait time or at least make it more bearable. ${ }^{3,28,41}$ Informing the patient with frequent updates and keeping their anxieties in mind can also increase satisfaction.

\section{Patient Expectations}

Patient expectations about treatment have a complex relationship with satisfaction. . $^{12,24,25,38}$ Some researchers have found that satisfaction is closely related to expecta- 
tions patients have about the care to be provided and that the outcome can be less important. ${ }^{5,16,39}$ Patients generally have high expectations for improvement with spine surgery, sometimes to an unrealistic extent. ${ }^{30}$ Patients may be dissatisfied when the recommended treatments, or lack thereof, do not meet their expectations. In an era in which assessment tools have been developed to measure expectation fulfillment as one measure of quality care,${ }^{10}$ more precisely understanding the relationship between patient expectations and satisfaction for spinal disorders is important.

We found that among patients referred to neurosurgeons for a surgical opinion, patients who received a recommendation against surgical intervention reported lower satisfaction scores than those who received a recommendation for surgery. Patients who are referred to a surgeon for a consultation may have the expectation that a surgical intervention is necessary to help manage their pain and disability. When such patients are not offered surgery, dissatisfaction may result from unmet expectations. The Press Ganey medical practice survey does not include items that address patient expectations explicitly, so the underlying reasons why patients who were not offered surgery had lower satisfaction scores are not apparent. Moreover, lower satisfaction scores cannot be explained by unmet expectations alone. We surveyed patients presenting for new spine consultations. Prior research has shown that people tend not to have fully developed expectations when encountering a system for the first time. ${ }^{2}$ Expectations emerge during the interaction with the physician rather than beforehand. ${ }^{38}$ Therefore, counseling these patients on nonoperative treatment strategies and educating them on why surgery is not recommended may help improve their experience. Nonetheless, future studies evaluating patient satisfaction should determine the underlying reasons for high or low satisfaction scores and whether there is an association between satisfaction and met or unmet expectations.

\section{Limitations}

One of the limitations to this study is the use of the ODI to quantitate disability. Although many investigators have assumed that the ODI correlates linearly with disability, it is not possible to define the mathematical behavior of this scale. ${ }^{7}$ For example, a patient with a percentage score of $40 \%$ is unlikely to be twice as disabled as one with a score of $20 \%$ because the structure of several items on the ODI is not linear. Therefore, while we found a significant difference between satisfaction in patients with severe pain and disability and satisfaction in those with milder symptoms, this relationship is most likely complex and nonlinear. By aggregating the ODI into two categories of disability severity, we were able to include analysis of the affect of disability on satisfaction without making mathematical assumptions about the behavior of the ODI scale. Other groups have used an ODI of $40 \%$ as a criterion for dividing a study population into groups according to severity.,36 We consider an ODI percentage threshold of $40 \%$ to separate mild to moderate self-assessed disability from severe disability to be appropriate given that one study reported a weighted ODI of 27 after aggregating data from 2166 patients with primary back pain.? Thus, our criterion of $\geq$
$40 \%$ would indicate disability that is more severe than the average patient with back pain.

The timing of survey completion in relation to the clinic visit may also influence the satisfaction score. Surveys administered outside the context of an immediate visit may be a proxy for symptom or functional improvement rather than a measure of satisfaction during the health care encounter. ${ }^{20,21}$ If the intention is to measure satisfaction with specific physician behavior or patient experiences, the survey ideally should be administered immediately after the visit. Delays may introduce lower response rates and nonresponse bias. In our study, patients were mailed surveys approximately 1 week after their clinic visit, and the response time was not tracked, but because our study population consisted of patients seen electively in an outpatient clinic for an initial surgical consultation for back pain, the patients should not have had an expectation for improvement in functional status at the time of the survey since no surgical intervention was performed at the clinic visit.

This questionnaire-based study is also subject to recall bias. Study results are derived from voluntary responses. Patients who are either very satisfied or very dissatisfied with their outpatient health care experience may be more likely to respond than those with neutral experiences. Extreme satisfaction scores may be related to whether the surgeon's treatment recommendation matched patients' expectations, but this hypothesis needs to be tested directly in a prospective trial. Whether the demographic characteristics of survey nonresponders were similar to those of responders is unclear. Such information will help ensure that our findings are generalizable. We were not able to review demographic and clinical information on patients who declined to complete satisfaction surveys. Future prospective studies should track relevant information for both responders and nonresponders alike.

\section{Conclusions}

We describe factors that may negatively affect satisfaction surveys among patients with spinal disorders who present for new outpatient consultations. Disability selfassessed by ODI percentage score and recommendation against surgical intervention were associated with lower patient satisfaction.

\section{References}

1. Anderson RT, Camacho FT, Balkrishnan R: Willing to wait? the influence of patient wait time on satisfaction with primary care. BMC Health Serv Res 7:31, 2007

2. Avis M, Bond M, Arthur A: Questioning patient satisfaction: an empirical investigation in two outpatient clinics. Soc Sci Med 44:85-92, 1997

3. Baker J, Cameron M: The effects of the service environment on affect and consumer perception of waiting time: an integrative review and research propositions. J Acad Mark Sci 24:338-349, 1996

4. Centers for Medicare \& Medicaid Services: Medicare Program; Hospital Inpatient Prospective Payment Systems for Acute Care Hospitals and the Long-Term Care Hospital Prospective Payment System and Fiscal Year 2014 Rates; Quality Reporting Requirements for Specific Providers; Hospital Conditions of Participation; Payment Policies Related 
to Patient Status. Federal Register. (https://federalregister. gov/a/2013-18956) [Accessed February 10, 2015]

5. Cleary PD, McNeil BJ: Patient satisfaction as an indicator of quality care. Inquiry 25:25-36, 1988

6. Cohen G: Age and health status in a patient satisfaction survey. Soc Sci Med 42:1085-1093, 1996

7. Fairbank JC, Pynsent PB: The Oswestry Disability Index. Spine (Phila Pa 1976) 25:2940-2952, 2000

8. Fenton JJ, Jerant AF, Bertakis KD, Franks P: The cost of satisfaction: a national study of patient satisfaction, health care utilization, expenditures, and mortality. Arch Intern Med 172:405-411, 2012

9. Fitzpatrick R, Hopkins A: Problems in the conceptual framework of patient satisfaction research: an empirical exploration. Sociol Health Illn 5:297-311, 1983

10. Hafferty FW, Light DW: Professional dynamics and the changing nature of medical work. J Health Soc Behav (Spec No):132-153, 1995

11. Hall JA, Dornan MC: Patient sociodemographic characteristics as predictors of satisfaction with medical care: a metaanalysis. Soc Sci Med 30:811-818, 1990

12. Hall JA, Dornan MC: What patients like about their medical care and how often they are asked: a meta-analysis of the satisfaction literature. Soc Sci Med 27:935-939, 1988

13. Hall JA, Feldstein M, Fretwell MD, Rowe JW, Epstein AM: Older patients' health status and satisfaction with medical care in an HMO population. Med Care 28:261-270, 1990

14. Hall JA, Milburn MA, Epstein AM: A causal model of health status and satisfaction with medical care. Med Care 31:8494, 1993

15. Hall JA, Milburn MA, Roter DL, Daltroy LH: Why are sicker patients less satisfied with their medical care? Tests of two explanatory models. Health Psychol 17:70-75, 1998

16. Hall JA, Roter DL, Katz NR: Meta-analysis of correlates of provider behavior in medical encounters. Med Care 26:657675,1988

17. Hall JA, Roter DL, Milburn MA: Illness and satisfaction with medical care. Curr Dir Psychol Sci 8:96-99, 1999

18. Hekkert KD, Cihangir S, Kleefstra SM, van den Berg B, Kool RB: Patient satisfaction revisited: a multilevel approach. Soc Sci Med 69:68-75, 2009

19. Institute of Medicine Committee on Quality of Health Care in America: Crossing the Quality Chasm: A New Health System for the 21st Century. Washington, DC: National Academy Press, 2001

20. Jackson JL, Chamberlin J, Kroenke K: Predictors of patient satisfaction. Soc Sci Med 52:609-620, 2001

21. Jatulis DE, Bundek NI, Legorreta AP: Identifying predictors of satisfaction with access to medical care and quality of care. Am J Med Qual 12:11-18, 1997

22. Jenkinson C, Coulter A, Bruster S, Richards N, Chandola T: Patients' experiences and satisfaction with health care: results of a questionnaire study of specific aspects of care. Qual Saf Health Care 11:335-339, 2002

23. Leddy KM, Kaldenberg DO, Becker BW: Timeliness in ambulatory care treatment. An examination of patient satisfaction and wait times in medical practices and outpatient test and treatment facilities. J Ambul Care Manage 26:138-149, 2003

24. Linder-Pelz S: Social psychological determinants of patient satisfaction: a test of five hypothesis. Soc Sci Med 16:583589,1982

25. Linder-Pelz SU: Toward a theory of patient satisfaction. Soc Sci Med 16:577-582, 1982

26. Linn LS, Greenfield S: Patient suffering and patient satisfaction among the chronically ill. Med Care 20:425-431, 1982

27. Lyu H, Wick EC, Housman M, Freischlag JA, Makary MA: Patient satisfaction as a possible indicator of quality surgical care. JAMA Surg 148:362-367, 2013
28. Maister D: The psychology of waiting lines, in Czepiel J, Soloman M, Suprenant CF (eds): The Service Encounter: Managing Employee/Customer Interaction in Service Business. Lexington, MA: Lexington Books, 1985, pp 113123

29. Manary MP, Boulding W, Staelin R, Glickman SW: The patient experience and health outcomes. N Engl J Med 368:201-203, 2013

30. McGregor AH, Hughes SP: The evaluation of the surgical management of nerve root compression in patients with low back pain: Part 2: patient expectations and satisfaction. Spine (Phila Pa 1976) 27:1471-1477, 2002

31. Michael M, Schaffer SD, Egan PL, Little BB, Pritchard PS: Improving wait times and patient satisfaction in primary care. J Healthc Qual 35:50-59, 2013

32. Pascoe GC: Patient satisfaction in primary health care: a literature review and analysis. Eval Program Plann 6:185210, 1983

33. Press Ganey Associates: Pulse Report 2009: Emergency Department. Patient Perspectives on American Health Care. (http://www.pressganey.com/Documents_secure/ Pulse\%20Reports/2009_ED_Pulse_Report.pdf) [Accessed February 12, 2015]

34. Press Ganey Associates: 2011 Pulse Report: Perspectives on American Health Care. (http://www.pressganey.com/ Documents_secure/Pulse\%20Reports/2011_Press_Ganey_ Pulse_Report.pdf) [Accessed February 10, 2015]

35. Rademakers J, Delnoij D, de Boer D: Structure, process or outcome: which contributes most to patients' overall assessment of healthcare quality? BMJ Qual Saf 20:326-331, 2011

36. Sanderson PL, Todd BD, Holt GR, Getty CJ: Compensation, work status, and disability in low back pain patients. Spine (Phila Pa 1976) 20:554-556, 1995

37. Sixma HJ, Spreeuwenberg PM, van der Pasch MA: Patient satisfaction with the general practitioner: a two-level analysis. Med Care 36:212-229, 1998

38. Thompson AG, Suñol R: Expectations as determinants of patient satisfaction: concepts, theory and evidence. Int J Qual Health Care 7:127-141, 1995

39. Verbeek J, Sengers MJ, Riemens L, Haafkens J: Patient expectations of treatment for back pain: a systematic review of qualitative and quantitative studies. Spine (Phila Pa 1976) 29:2309-2318, 2004

40. Vuori H: Patient satisfaction - an attribute or indicator of the quality of care? QRB Qual Rev Bull 13:106-108, 1987

41. Zeithaml VA, Bitner MJ: Services Marketing. New York: McGraw-Hill, 1996

\section{Author Contributions}

Conception and design: Bisson, Schmidt. Acquisition of data: Mazur, McEvoy. Analysis and interpretation of data: Bisson, Mazur. Drafting the article: Mazur. Critically revising the article: all authors. Reviewed submitted version of manuscript: all authors. Approved the final version of the manuscript on behalf of all authors: Bisson. Study supervision: Bisson, Schmidt.

\section{Supplemental Information}

\section{Previous Presentation}

This paper was presented at the 30th Annual Meeting of the AANS/CNS Section on Disorders of the Spine and Peripheral Nerves, Orlando, Florida, March 2014.

\section{Correspondence}

Erica F. Bisson, Department of Neurosurgery, University of Utah, 175 N. Medical Dr. E, Salt Lake City, UT 84132. email: erica. bisson@hsc.utah.edu. 